\title{
Major Pharmaceutical Conferences and Courses: June to July 2022
}

\begin{tabular}{|c|c|c|c|c|c|}
\hline Starts & Ends & Conference title & Location & Sponsor & Website \\
\hline 01-Jun-22 & 04-Jun-22 & $\begin{array}{l}\text { Progress in Vaccine Devel- } \\
\text { opment for Infectious } \\
\text { Diseases }\end{array}$ & $\begin{array}{l}\text { Breckenridge, CO, } \\
\text { USA }\end{array}$ & Keystone Symposia & $\begin{array}{l}\text { www.keystonesy } \\
\text { mposia.org }\end{array}$ \\
\hline 02-Jun-22 & 03-Jun-22 & $\begin{array}{l}\text { Regulatory Considerations } \\
\text { for Advanced Therapies } \\
\text { \& RNA-based Thera- } \\
\text { peutics }\end{array}$ & Virtual & $\begin{array}{l}\text { Regulatory Affairs Pro- } \\
\text { fessionals Society }\end{array}$ & www.raps.org \\
\hline 05-Jun-22 & 09-Jun-22 & $\begin{array}{l}\text { Neurodegeneration: The } \\
\text { Biological Pathways } \\
\text { Driving the Future of } \\
\text { Therapeutic Development }\end{array}$ & Keystone, CO, USA & Keystone Symposia & $\begin{array}{l}\text { www.keystonesy } \\
\text { mposia.org }\end{array}$ \\
\hline 06-Jun-22 & 08-Jun-22 & $\begin{array}{l}\text { Decentralized Clinical } \\
\text { Trials }\end{array}$ & Miami, FL, USA & Informa Connect & $\begin{array}{l}\text { www.informacon } \\
\text { nect.com }\end{array}$ \\
\hline 07-Jun-22 & 07-Jun-22 & $\begin{array}{l}\text { Regulation of Drug Device } \\
\text { Combination Products }\end{array}$ & Brussels, Belgium & $\begin{array}{l}\text { The Organisation for Pro- } \\
\text { fessionals in Regulatory } \\
\text { Affairs }\end{array}$ & www.topra.org \\
\hline 07-Jun-22 & 08-Jun-22 & $\begin{array}{l}\text { Drug/Device and Device/ } \\
\text { Drug Combinations in } \\
\text { the EU (European Union) } \\
\text { and USA }\end{array}$ & London, England & Management Forum & $\begin{array}{l}\text { www.management- } \\
\text { forum.co.uk }\end{array}$ \\
\hline 07-Jun-22 & 08-Jun-22 & $\begin{array}{l}\text { Medical Device Studies: } \\
\text { Regulatory Require- } \\
\text { ments and Adverse Event } \\
\text { Reporting }\end{array}$ & London, England & Management Forum & $\begin{array}{l}\text { www.management- } \\
\text { forum.co.uk }\end{array}$ \\
\hline 07-Jun-22 & 09-Jun-22 & $\begin{array}{l}\text { Advanced Pharmacovigi- } \\
\text { lance }\end{array}$ & London, England & Management Forum & $\begin{array}{l}\text { www.management- } \\
\text { forum.co.uk }\end{array}$ \\
\hline 07-Jun-22 & 09-Jun-22 & $\begin{array}{l}\text { Pharmaceutical Compli- } \\
\text { ance Congress Canada }\end{array}$ & Toronto, ON, USA & Informa Connect & $\begin{array}{l}\text { www.informacon } \\
\text { nect.com }\end{array}$ \\
\hline 07-Jun-22 & 09-Jun-22 & $\begin{array}{l}\text { A Systems Approach to } \\
\text { Good Pharmacovigilance } \\
\text { Practice }\end{array}$ & Cambridge, England & $\begin{array}{l}\text { The Research Quality } \\
\text { Association }\end{array}$ & www.therqa.com \\
\hline 08-Jun-22 & 10-Jun-22 & $\begin{array}{l}\text { Regulatory Control of } \\
\text { Clinical Operations }\end{array}$ & London, England & $\begin{array}{l}\text { The Organisation for Pro- } \\
\text { fessionals in Regulatory } \\
\text { Affairs }\end{array}$ & www.topra.org \\
\hline 08-Jun-22 & 09-Jun-22 & $\begin{array}{l}\text { Outsourcing in Clinical } \\
\text { Trials: Medical Devices } \\
\text { USA }\end{array}$ & Irvine, CA, USA & Arena International & $\begin{array}{l}\text { www.arena-inter } \\
\text { national.com }\end{array}$ \\
\hline 09-Jun-22 & 10-Jun-22 & $\begin{array}{l}\text { Statistics and Data Man- } \\
\text { agement }\end{array}$ & Virtual & $\begin{array}{l}\text { Faculty of Pharmaceuti- } \\
\text { cal Medicine }\end{array}$ & www.fpm.org.uk \\
\hline 10-Jun-22 & 08-Jun-22 & $\begin{array}{l}\text { Medical Aspects of } \\
\text { Adverse Drug Reactions }\end{array}$ & Whiteley, England & $\begin{array}{l}\text { Drug Safety Research } \\
\text { Unit }\end{array}$ & www.dsru.org \\
\hline
\end{tabular}




\begin{tabular}{|c|c|c|c|c|c|}
\hline Starts & Ends & Conference title & Location & Sponsor & Website \\
\hline 13-Jun-22 & 14-Jun-22 & $\begin{array}{c}\text { Clinical Data Disclosure, } \\
\text { Transparency and Plain } \\
\text { Language Summaries }\end{array}$ & Miami, FL, USA & Informa Connect & $\begin{array}{l}\text { www.informacon } \\
\text { nect.com }\end{array}$ \\
\hline 13-Jun-22 & 16-Jun-22 & $\begin{array}{l}\text { BIO International Conven- } \\
\text { tion }\end{array}$ & San Diego, CA, USA & $\begin{array}{l}\text { Biotechnology Industry } \\
\text { Organization }\end{array}$ & www.bio.org \\
\hline 13-Jun-22 & 17-Jun-22 & $\begin{array}{l}\text { The Medical Device } \\
\text { School: From Concept to } \\
\text { CE Marking }\end{array}$ & Virtual & Management Forum & $\begin{array}{l}\text { www.management- } \\
\text { forum.co.uk }\end{array}$ \\
\hline 14-Jun-22 & 14-Jun-22 & $\begin{array}{l}\text { CRED Successful and Skil- } \\
\text { ful Communication }\end{array}$ & London, England & $\begin{array}{l}\text { The Organisation for Pro- } \\
\text { fessionals in Regulatory } \\
\text { Affairs }\end{array}$ & www.topra.org \\
\hline 14-Jun-22 & 15-Jun-22 & $\begin{array}{l}\text { Outsourcing in Clinical Tri- } \\
\text { als: UK \& Ireland } 2022\end{array}$ & London, England & Arena International & $\begin{array}{l}\text { www.arena-inter } \\
\text { national.com }\end{array}$ \\
\hline 15-Jun-22 & 16-Jun-22 & $\begin{array}{l}\text { Global Pharmacovigilance } \\
\text { Regulatory Requirements: } \\
\text { What's New? }\end{array}$ & London, England & $\begin{array}{l}\text { Drug Safety Research } \\
\text { Unit }\end{array}$ & www.dsru.org \\
\hline 15-Jun-22 & 16-Jun-22 & $\begin{array}{l}\text { Medical Device Regula- } \\
\text { tions in the Middle East } \\
\text { and North Africa }\end{array}$ & Virtual & Management Forum & $\begin{array}{l}\text { www.management- } \\
\text { forum.co.uk }\end{array}$ \\
\hline 16-Jun-22 & 16-Jun-22 & $\begin{array}{l}\text { Good Clinical Practice and } \\
\text { Clinical Research Update: } \\
\text { Hot Inspection Topics }\end{array}$ & Virtual & Management Forum & $\begin{array}{l}\text { www.management- } \\
\text { forum.co.uk }\end{array}$ \\
\hline 19-Jun-22 & 23-Jun-22 & $\begin{array}{l}\text { DIA } 2022 \text { Global Annual } \\
\text { Meeting }\end{array}$ & Chicago, IL, USA & $\begin{array}{l}\text { Drug Information Asso- } \\
\text { ciation }\end{array}$ & www.diaglobal.org \\
\hline 20-Jun-22 & 21-Jun-22 & $\begin{array}{l}\text { The FDA Drug Approval } \\
\text { Process }\end{array}$ & London, England & Management Forum & $\begin{array}{l}\text { www.management- } \\
\text { forum.co.uk }\end{array}$ \\
\hline 20-Jun-22 & 21-Jun-22 & $\begin{array}{l}\text { Project Management for } \\
\text { Pharma Professionals }\end{array}$ & London, England & Management Forum & $\begin{array}{l}\text { www.management- } \\
\text { forum.co.uk }\end{array}$ \\
\hline 20-Jun-22 & 22-Jun-22 & $\begin{array}{l}\text { 17th Annual Biomarkers } \\
\text { \& Precision Oncology } \\
\text { World Congress }\end{array}$ & Boston, MA, USA & $\begin{array}{l}\text { Cambridge Healthtech } \\
\text { Institute }\end{array}$ & $\begin{array}{l}\text { www.healthtech. } \\
\text { com }\end{array}$ \\
\hline 20-Jun-22 & 23-Jun-22 & $\begin{array}{l}\text { Gene Regulation: From } \\
\text { Emerging Technologies } \\
\text { to New Models }\end{array}$ & Santa Fe, NM, USA & Keystone Symposia & $\begin{array}{l}\text { www.keystonesy } \\
\text { mposia.org }\end{array}$ \\
\hline 20-Jun-22 & 24-Jun-22 & MedTech Summit 2022 & Dublin, Ireland & Informa Connect & $\begin{array}{l}\text { www.informacon } \\
\text { nect.com }\end{array}$ \\
\hline 21-Jun-22 & 22-Jun-22 & The Auditing Course & Cambridge, England & $\begin{array}{l}\text { The Research Quality } \\
\text { Association }\end{array}$ & www.therqa.com \\
\hline 21-Jun-22 & 23-Jun-22 & Pharmacovigilance & Virtual & Management Forum & $\begin{array}{l}\text { www.management- } \\
\text { forum.co.uk }\end{array}$ \\
\hline 22-Jun-22 & 23-Jun-22 & $\begin{array}{l}\text { FDA Approval Process for } \\
\text { Medical Devices }\end{array}$ & London, England & Management Forum & $\begin{array}{l}\text { www.management- } \\
\text { forum.co.uk }\end{array}$ \\
\hline 27-Jun-22 & 27-Jun-22 & $\begin{array}{l}\text { Regulatory Strategies for } \\
\text { Orphan Drugs }\end{array}$ & London, England & Management Forum & $\begin{array}{l}\text { www.management- } \\
\text { forum.co.uk }\end{array}$ \\
\hline 27-Jun-22 & 30-Jun-22 & $\begin{array}{l}\text { Quality Management Vir- } \\
\text { tual Conference }\end{array}$ & Virtual & $\begin{array}{l}\text { Society of Clinical } \\
\text { Research Associates }\end{array}$ & www.socra.org \\
\hline 28-Jun-22 & 28-Jun-22 & $\begin{array}{l}\text { eClinical \& Clinical Data } \\
\text { Management Innovation } \\
\text { Conference } 2022\end{array}$ & Virtual & Arena International & $\begin{array}{l}\text { www.arena-inter } \\
\text { national.com }\end{array}$ \\
\hline 28-Jun-22 & 29-Jun-22 & $\begin{array}{l}\text { CRED Managing Lifecycle } \\
\text { and Variations Effectively }\end{array}$ & London, England & $\begin{array}{l}\text { The Organisation for Pro- } \\
\text { fessionals in Regulatory } \\
\text { Affairs }\end{array}$ & www.topra.org \\
\hline 28-Jun-22 & 30-Jun-22 & $\begin{array}{c}\text { African Regional Interest } \\
\text { Group Virtual Meeting }\end{array}$ & Virtual & $\begin{array}{l}\text { International Society for } \\
\text { Pharmacoepidemiology }\end{array}$ & $\begin{array}{l}\text { www.pharmacoepi. } \\
\text { org }\end{array}$ \\
\hline 29-Jun-22 & 30-Jun-22 & $\begin{array}{l}\text { Pharmaceutical Regulatory } \\
\text { Affairs in the Middle East }\end{array}$ & Virtual & Management Forum & $\begin{array}{l}\text { www.management- } \\
\text { forum.co.uk }\end{array}$ \\
\hline
\end{tabular}




\begin{tabular}{|c|c|c|c|c|c|}
\hline Starts & Ends & Conference title & Location & Sponsor & Website \\
\hline 29-Jun-22 & 02-Jul-22 & $\begin{array}{l}\text { Viral Immunity: Basic } \\
\text { Mechanisms and Thera- } \\
\text { peutic Applications }\end{array}$ & Keystone, CO, USA & Keystone Symposia & $\begin{array}{l}\text { www.keystonesy } \\
\text { mposia.org }\end{array}$ \\
\hline 05-Jul-22 & 07-Jul-22 & $\begin{array}{l}\text { The Medical Device Intro- } \\
\text { ductory Course }\end{array}$ & London, England & $\begin{array}{l}\text { The Organisation for Pro- } \\
\text { fessionals in Regulatory } \\
\text { Affairs }\end{array}$ & www.topra.org \\
\hline 05-Jul-22 & 06-Jul-22 & $\begin{array}{l}\text { Medical Device Regulation } \\
\text { in the Eurasian Union, } \\
\text { Russia and the CIS }\end{array}$ & London, England & Management Forum & $\begin{array}{l}\text { www.management- } \\
\text { forum.co.uk }\end{array}$ \\
\hline 07-Jul-22 & 08-Jul-22 & $\begin{array}{l}\text { Clinical Development and } \\
\text { Discovery Medicine }\end{array}$ & Virtual & $\begin{array}{l}\text { Faculty of Pharmaceuti- } \\
\text { cal Medicine }\end{array}$ & www.fpm.org.uk \\
\hline 11-Jul-22 & 11-Jul-22 & $\begin{array}{l}\text { A Practical Guide to Writ- } \\
\text { ing Risk Management } \\
\text { Plans }\end{array}$ & Virtual & Management Forum & $\begin{array}{l}\text { www.management- } \\
\text { forum.co.uk }\end{array}$ \\
\hline 11-Jul-22 & 11-Jul-22 & Filing eCTD Submissions & London, England & Management Forum & $\begin{array}{l}\text { www.management- } \\
\text { forum.co.uk }\end{array}$ \\
\hline 11-Jul-22 & 13-Jul-22 & $\begin{array}{l}\text { World Orphan Drug Con- } \\
\text { gress USA } 2022\end{array}$ & Boston, MA, USA & Terrapinn & www.terrapinn.com \\
\hline 12-Jul-22 & 12-Jul-22 & $\begin{array}{l}\text { A Practical Guide to Pro- } \\
\text { ducing and Maintaining } \\
\text { the PSMF }\end{array}$ & Virtual & Management Forum & $\begin{array}{l}\text { www.management- } \\
\text { forum.co.uk }\end{array}$ \\
\hline 12-Jul-22 & 13-Jul-22 & $\begin{array}{l}\text { Clinical Operations in } \\
\text { Oncology Trials East } \\
\text { Coast } 2022\end{array}$ & Boston, MA, USA & Arena International & $\begin{array}{l}\text { www.arena-inter } \\
\text { national.com }\end{array}$ \\
\hline 13-Jul-22 & 15-Jul-22 & $\begin{array}{l}\text { Clinical Site Coordina- } \\
\text { tor/Manager and GCP } \\
\text { Workshop }\end{array}$ & Virtual & $\begin{array}{l}\text { Society of Clinical } \\
\text { Research Associates }\end{array}$ & www.socra.org \\
\hline 14-Jul-22 & 15-Jul-22 & $\begin{array}{l}\text { Clinical Trial Regulatory } \\
\text { Requirements }\end{array}$ & Virtual & Management Forum & $\begin{array}{l}\text { www.management- } \\
\text { forum.co.uk }\end{array}$ \\
\hline 19-Jul-22 & 22-Jul-22 & $\begin{array}{l}\text { Clinical Research Monitor- } \\
\text { ing and GCP Virtual } \\
\text { Workshop }\end{array}$ & Virtual & $\begin{array}{l}\text { Society of Clinical } \\
\text { Research Associates }\end{array}$ & www.socra.org \\
\hline 26-Jul-22 & 29-Jul-22 & $\begin{array}{l}\text { Canadian Regulatory } \\
\text { Conference }\end{array}$ & Virtual & $\begin{array}{l}\text { Society of Clinical } \\
\text { Research Associates }\end{array}$ & www.socra.org \\
\hline
\end{tabular}

All events are subject to change. Many events offer a virtual attendance option in addition to the location listed. 